\title{
As concepções de jovens estudantes sobre assuntos históricos
}

The Conceptions of Young Students on Historical Subjects

Aaron Sena Cerqueira Reis*

\section{Resumo}

Neste artigo, objetiva-se compreender as concepções de jovens estudantes sobre assuntos históricos. A partir das contribuições epistemológicas do Ensino de História, consideramos as respostas apresentadas pelos/as informantes a um instrumento de pesquisa composto pela questão "Qual assunto da História você considera mais importante? Explique por quê". As respostas dos 199 participantes foram analisadas segundo os pressupostos da Grounded Theory. Com esse método, identificamos diferentes conceitos que foram categorizados em um dendograma composto por três classes. Esse processo foi auxiliado pelo IRaMuTeQ, software que viabiliza diferentes tipos de análise textual com base na frequência das palavras. Os resultados mostraram concepções ligadas a uma perspectiva tradicional de história, exemplificada com os assuntos relativos à história do Brasil, e a uma percepção da história geral, sobretudo a partir da abordagem da história do tempo presente.

Palavras-chave: ensino de história; concepções históricas; estudantes.

\section{Abstract}

The objective in this article is to understand the conceptions of young students on historical subjects. From the epistemological contributions of History teaching, we consider the answers presented by the informants to a research instrument composed of the following question: "What is the subject of History that you consider most important? Explain why". The responses of the 199 participants were analyzed according to Grounded Theory assumptions. With this method, we identified different concepts that were categorized into a dendogram composed of three classes. This process was aided by IRaMuTeQ, software that enables different types of textual analysis based on the frequency of words. The results showed conceptions linked to a traditional perspective of history, exemplified with the subjects related to the history of Brazil, and to a perception of the general history, especially from the approach of the history of the present time.

Keywords: history teaching; historical conceptions; students.

\footnotetext{
* Universidade Tiradentes (Unit-SE), Aracaju, Sergipe, Brasil. aaron_sena@hotmail.com
} 
Este trabalho se insere em um conjunto de produções que valorizam os processos de ensino-aprendizagem da História, sobretudo, no ambiente escolar, onde as construções mentais de professores/as e estudantes podem ser tomadas como objeto de estudo. Desse modo, visamos contribuir com o fortalecimento de um campo de estudos e pesquisa que, no Brasil, foi definido como Ensino de História. Resultado de um amplo debate iniciado na década de 1980, o Ensino de História privilegiou temas que perpassaram a construção de seu estatuto científico, bem como os desafios de sua prática, a exemplo da formação de professores, da produção do conhecimento escolar, dos usos do livro didático e suas diferentes linguagens e das reformas curriculares, além da implementação de políticas educacionais (Guimarães, 2012; Oliveira, 2003).

Para Maria Auxiliadora Schmidt (2012), o Ensino de História atravessou diferentes fases que contribuíram para a definição de um "código disciplinar" baseado nos processos de escolarização e formação da cultura escolar. Inicialmente, com a fase de "construção" (1838-1931), destacou-se "a necessidade de definição de uma identidade nacional" por meio de uma "pedagogização" da história. Em seguida, houve uma "consolidação" (1931-1971), marcada por reformas educacionais que contribuíram para o aperfeiçoamento do método do Ensino de História. A terceira fase pode ser caracterizada como um momento de "crise" (1971-1984), tendo em vista a gradativa ampliação dos Estudos Sociais e a limitação do Ensino de História ao antigo $2^{\circ}$ Grau. Marcada pelo fim da ditadura militar, a última fase representou uma "reconstrução do código disciplinar da história no Brasil" (1984-?), consolidada com a produção de documentos como os Parâmetros Curriculares Nacionais (PCNs).

Essa última etapa representou uma valorização da História como disciplina escolar e, a partir dela, intensificaram-se, também, as pesquisas acerca do seu ensino que, de acordo com Circe Bittencourt (2011a), podem ser analisadas em dois momentos. O primeiro deles (1988-1996) visava subsidiar os debates em torno das reformulações curriculares em voga no país, as quais reintroduziam as disciplinas anteriormente substituídas pelos Estudos Sociais. No segundo momento (1997-2009), as pesquisas sobre (história do) Ensino de História se consolidavam em virtude de diferentes aspectos, como a ampliação da noção de fonte histórica e a aproximação com outras áreas do conhecimento, o que 
favoreceu, também, "a incorporação dos alunos e dos professores como sujeitos da constituição da História como disciplina escolar” (Bittencourt, 2011a, p. 93).

Em que pesem as diferentes abordagens, é possível identificar uma série de estudos preocupados com o olhar de estudantes e professores acerca da disciplina ou do conhecimento histórico, tanto pela perspectiva da Didática da História quanto da Educação Histórica. Particularmente, acreditamos que as contribuições epistemológicas de ambas as categorias representam possibilidades de renovação para o Ensino de História. Desse modo, é possível nos debruçarmos sobre concepções, narrativas, aprendizagens ou, também, a consciência histórica dos diferentes sujeitos em situação escolar (Pina; Silva, 2017; Schmidt, 2008; Schmidt; Garcia, 2005).

Pensando nessa realidade, objetivamos neste artigo compreender as concepções de estudantes do Ensino Básico sobre assuntos históricos. Em outras palavras, queremos entender quais os temas mais recorrentes, bem como perceber a importância que os jovens atribuem aos conteúdos selecionados. Afinal de contas, é "a partir da práxis dos alunos que o professor identifica o conhecimento histórico que ele considera significativo" (Saddi, 2016, p. 118). Com isso, esperamos ressaltar o papel do estudante como um agente ativo no processo de aprendizagem. Acreditamos que, ao conhecer as disposições internas do jovem, o/a professor/a tende a mediar o conhecimento produzido em sala de aula e, assim, talvez possa contribuir com a formação de um pensamento histórico mais crítico.

\section{Percurso metodológico}

Neste artigo, seguimos os pressupostos da investigação qualitativa, a qual preconiza a necessidade de observação do objeto em seu ambiente natural e cuja forma de apresentação é basicamente descritiva. Nessa perspectiva, nosso posicionamento recaiu sobre o processo e, por isso, nossas abstrações foram construídas ao longo da pesquisa. Assim, estivemos interessados nos modos como os sujeitos experimentaram e interpretaram o fenômeno observado e atribuíram sentidos a ele (Bogdan; Biklen, 1994).

O estudo empírico foi realizado em uma escola pública estadual, localizada no bairro Butantã, na cidade de São Paulo (SP). Participaram 199 
estudantes, dos gêneros masculino, feminino e outros, entre 12 e 20 anos de idade, distribuídos em turmas do $7^{\circ}$ ano do Ensino Fundamental ao $3^{\circ}$ ano do Ensino Médio. Com a autorização de coordenadores e professores, realizamos um período de observação participante e, em seguida, aplicamos um instrumento para coleta de dados.

Inspirado em diferentes trabalhos (Moreno, 2006; Schmidt, 2008; Schmidt; Garcia, 2005; Ramos; Alves, 2016; Germinari, 2016), o instrumento de pesquisa contou com esta questão: "Qual assunto da História você considera mais importante? Explique por quê". Sendo uma pergunta aberta, o participante poderia informar aquilo que considerasse mais pertinente.

Baseando-nos na Grounded Theory de Strauss e Corbin (2008), buscamos estabelecer ou identificar conceitos, delimitando suas propriedades e dimensões para a compreensão do fenômeno estudado. As respostas apresentadas ao instrumento de pesquisa foram coligidas em um corpus documental denominado Assuntos Históricos e submetidas ao IRaMuTeQ, software que viabiliza diferentes tipos de análise textual. Por meio desse programa computacional realizamos uma Classificação Hierárquica Descendente (CHD), isto é, um tipo de análise multivariada que auxilia a construção de categorias baseadas na frequência das palavras, cuja representação gráfica é um dendograma (Camargo; Justo, 2013).

Com o IRaMuTeQ foi possível isolar palavras significativas em relação ao conjunto dos dados, facilitando nossa tarefa de atribuição de sentidos aos conceitos desvelados pelos/as informantes. Das 199 respostas - ou segmentos de texto (ST), na linguagem do programa -, o software considerou 173 $(86,93 \%)$ em sua análise. As respostas não foram longas e apresentaram uma ocorrência média de 15,35 palavras. O corpus foi constituído por 717 palavras distintas, com frequência média de 4,26. A CHD representada no Gráfico 1 viabilizou um exame "microscópico" dos dados por meio do qual evidenciamos diferentes categorias e as relações que elas estabelecem entre si (Strauss; Corbin, 2008). Para a sua construção, consideramos as palavras com frequência (f) igual ou superior a 3 e qui-quadrado $\left(\mathrm{x}^{2}\right)$ igual ou superior a 4,41 - este último coeficiente denota o poder de associação de uma palavra à classe. 
Gráfico 1 - CHD do corpus Assuntos Históricos

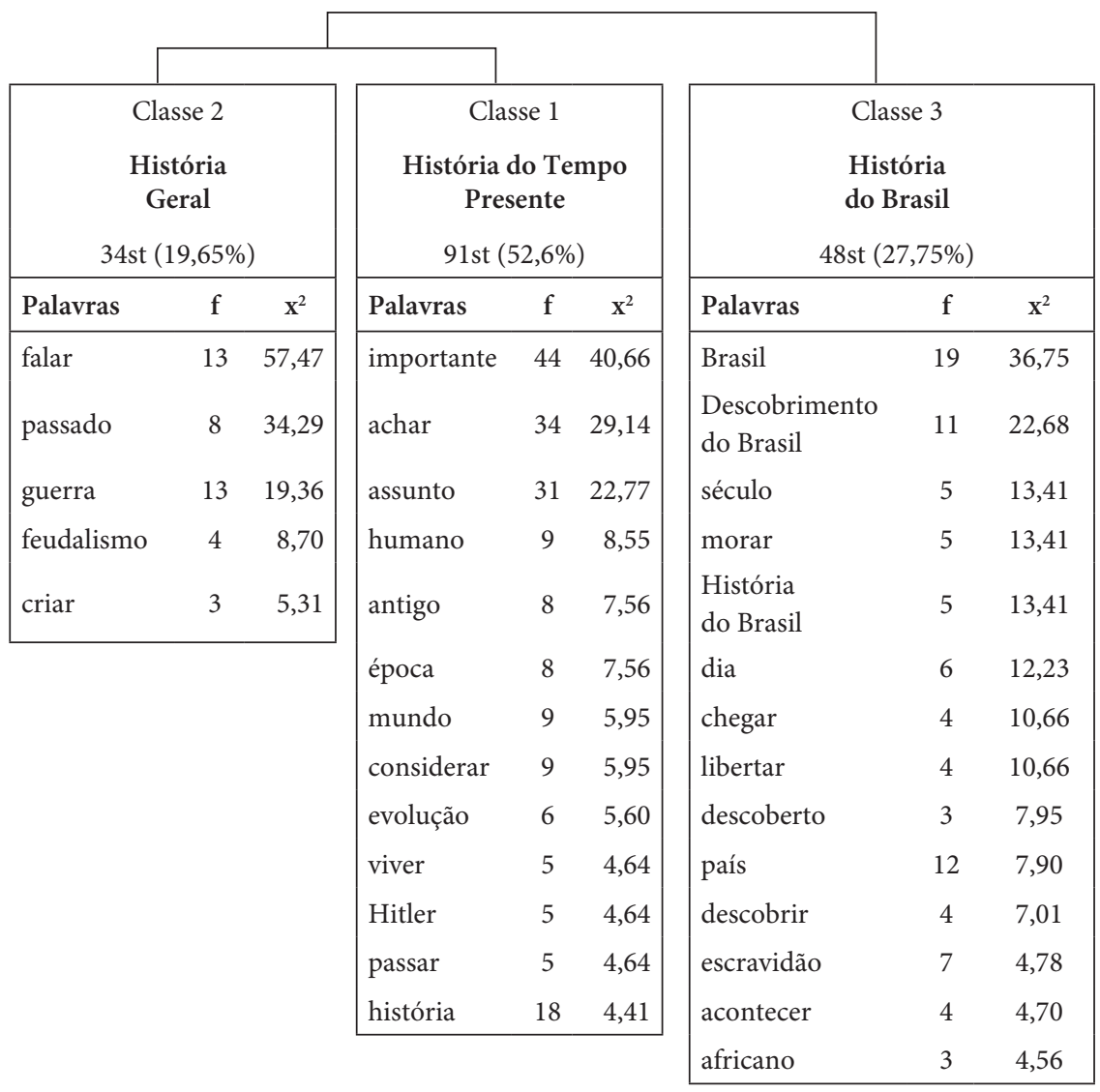

Fonte: Dendograma produzido com auxílio do IRaMuTeQ.

Conforme esse dendograma, o corpus Assuntos Históricos sofreu duas partições. A primeira delas isolou a classe 3, separando-a das demais. Já a segunda originou as classes 1 e 2. Nessa CHD observamos a predominância de alguns grupos: na primeira e na segunda classe, houve a predominância dos/ as participantes com 14 anos de idade $(69,77 \%)$ e que cursavam o $1^{\circ}$ ano do Ensino Médio (74,07\%); na terceira, estudantes do $7^{\circ}(43,75 \%)$ ou $8^{\circ}$ ano $(47,62 \%)$ do Ensino Fundamental, com idades entre 12 (42,11\%) e 13 anos (40\%). O número de segmentos de texto (ST) retido foi distribuído de maneira irregular. Logo, notamos uma maior representatividade da classe 1, constituída 
por $52,6 \%$ dos ST considerados na análise, seguida pelas classes 3, com $27,75 \%$ dos ST e, da classe 2, com 19,65\%. Adiante, analisaremos as três categorias que esboçam as concepções históricas dos estudantes.

\section{HiSTÓRIA DO TEMPO PRESENTE}

Inicialmente, percebemos que, embora apontem temas relativos ao "mundo" ( $\mathrm{f}=9$ ), os/as estudantes agrupados na classe 1 demonstram dificuldade em eleger um "assunto" ( $\mathrm{f}=31$ ) específico considerado "importante" $(\mathrm{f}=44)$. Em geral, esses/as jovens explicam que não há tema cujo valor seja superior a outro e, por esse motivo, discorrem sobre aquilo que lhes interessa ou que estudavam no momento da resposta ao instrumento de pesquisa:

O assunto que eu acho mais importante são as histórias sobre as descobertas no mundo. (estudante 232, gênero masculino, 17 anos, $3^{\circ}$ ano)

Para mim todos os assuntos têm sua importância, mesmo que alguns sejam mais precisos que outros. (estudante 180, gênero masculino, 15 anos, $2^{\circ}$ ano)

Eu não acho importante, mas sim, interessante, a Revolução Francesa, porque foi o assunto pelo qual mais me interessei e também por causa do professor que sabe dar uma aula. (estudante 130, gênero feminino, 14 anos, $8^{\circ}$ ano)

Estamos estudando sobre o Adolf Hitler, no momento e foi o único assunto que mais me chamou atenção. (estudante 11, gênero feminino, 14 anos, $9^{\circ}$ ano)

Mesmo resistentes, muitos/as conseguiram expor um tópico considerado importante para o estudo da história. Contudo, apenas uma parte teceu explicações sobre suas indicações:

É difícil dizer um assunto específico que eu acho mais importante. Já que são vários essenciais para os objetivos da história. Afinal, é necessário o todo para entender razoavelmente os outros tempos. O mais próximo de ser importante a qual considero, é o comportamento humano. Por que ele desencadeia muitos dos outros assuntos: as ferramentas, as máquinas, a tecnologia, a política e entre outras. (estudante 21, gênero feminino, 14 anos, $9^{\circ}$ ano)

Sobre a globalização, porque graças à globalização hoje podemos conversar com pessoas distantes e de outros países e também podemos saber sobre os 
acontecimentos de outros países, podemos procurar sobre qualquer assunto na internet e isso foi um grande passo na globalização e que proporcionou muito o nosso mundo. (estudante 222, gênero masculino, 17 anos, $3^{\circ}$ ano)

Os autores dessas respostas parecem sugerir temas cujo enfoque recai sobre a dinâmica das sociedades humanas, ou ainda, sobre a produção da história-problema, conforme preconizado pelo paradigma marxista e pela Escola dos Annales, respectivamente. Dessa forma, os estudantes nos permitem entrever a valorização dos fatos coletivos e sociais que contribuem para a construção de uma síntese histórica global dirigida às demandas do tempo presente. Mesmo isoladas, essas ideias evidenciam algumas das tendências historiográficas que são inseridas na prática do ensino de história (Bittencourt, 2011b).

Contudo, não estamos afirmando que os participantes tenham plena consciência das perspectivas científicas compartilhadas, provavelmente, pelo professor nas aulas de história ou, ainda, disponibilizadas em livros didáticos utilizados pelos jovens. Sugerimos, apenas, que nesses casos, o discurso proferido em ambiente escolar pode estar sendo apropriado na formação do pensamento histórico dos/as estudantes.

Ainda considerando as palavras mais frequentes da classe 1, observamos a indicação de conceitos que sugerem temas não necessariamente relacionados à história. A palavra "evolução" ( $\mathrm{f}=6$ ), por exemplo, poderia sugerir algum tipo de transformação, seja social ou cultural, ocorrida em diferentes espaços. Todavia, a conotação atribuída ao termo pelas narrativas que dele se apropriaram sugere outro tipo de "evolução", que não histórica. Tais narrativas o utilizam para explicar a capacidade humana de adaptação ao meio ambiente, semelhante à teoria da "evolução das espécies" como, por exemplo:

Achei bem importante a evolução dos humanos, como eles se adaptaram, se alimentaram e viveram. (estudante 141, gênero feminino, 17 anos, $1^{\circ}$ ano)

A origem da humanidade, como eram os costumes dos seres humanos, ou não exatamente humanos, mas sim descendentes de nós. A parte da evolução é uma coisa muito importante e interessante. (estudante 158, gênero masculino, 14 anos, $1^{\circ}$ ano)

A propósito, é comum a menção de "assuntos" pertencentes a outras áreas do conhecimento: 
Dinossauros, porque gosto muito desse assunto. É uma matéria que me interessa muito o estudo sobre os répteis. (estudante 146, gênero masculino, 14 anos, $1^{\circ}$ ano)

Para Katia Abud (2014, p. 19), situações como essa são comuns em âmbito escolar, já que alguns estudantes tendem a considerar o passado mais remoto como representativo de um evento ainda "mais histórico", mesmo não se tratando das experiências humanas no tempo, como no caso da "era dos dinossauros". Todavia, esses exemplos compõem uma exceção, visto que a maioria dos/as estudantes conseguiu definir temas relacionados, diretamente, a conceitos substantivos previstos em diferentes propostas curriculares, a exemplo da Proposta Curricular do Estado de São Paulo (2008) - onde a pesquisa foi realizada - para a disciplina de história. Entre esses conceitos estão aqueles relativos à personagens da história mundial, como "Hitler" $(\mathrm{f}=5)$ :

[...] No momento acho importante estarmos estudando isso, pois Hitler decretava que todos seguissem as regras dele e fossem como ele, mas nós não podemos ser assim, cada um tem sua maneira de pensar e fazer e por muitas outras coisas também. (estudante 11, gênero feminino, 14 anos, $9^{\circ}$ ano)

A Segunda Guerra Mundial. A Segunda Guerra foi onde as vítimas humanas estavam, quando mais perigo naquela época e com um cara como Hitler conseguiu fazer isso com a própria raça. (estudante 228, gênero masculino, 17 anos, $3^{\circ}$ ano) Estou gostando de estudar o nazi-fascismo pois foi um assunto que sempre me chamou a atenção nos anos anteriores e esse, e agora que estou estudando vou aproveitar ao máximo. Acho importante para sabermos como as ações de Hitler e Mussolini influenciaram o mundo de hoje. (estudante 12, gênero masculino, 14 anos, $9^{\circ}$ ano)

A Segunda Guerra Mundial, a história do Hitler e a tragédia da guerra e a burguesia, as três classes sociais e os contos e histórias do Egito. Porque essas histórias, acontecimento, foram as quais eu gostei mais de aprender e conhecer. Mas também depende, o professor quanto for melhor o professor for mais interessante eu vou achar. (estudante 140, gênero feminino, 15 anos, $1^{\circ}$ ano)

Essas narrativas discorrem, principalmente, sobre a Segunda Guerra Mundial e as formas de governo predominantes naquele momento, como o nazismo e o fascismo. Além de Hitler, também surge menção a outro personagem, o ditador italiano Mussolini. Abordados nas turmas de $9^{\circ}$ ano do Ensino 
Fundamental e de $3^{\circ}$ ano do Ensino Médio, acreditamos que esses temas e personagens sejam lembrados, não apenas pela proximidade com os estudos que eram realizados no momento da pesquisa, mas também pelo fato de despertarem a curiosidade, ou mesmo, a empatia dos/as jovens. Tal capacidade de identificação ocorre, provavelmente, em virtude da origem relativamente recente desses assuntos, os quais podem ser observados por meio de fontes audiovisuais, elementos presentes no cotidiano desses/as estudantes - e utilizados pelos professores, conforme percebemos durante a fase etnográfica da pesquisa.

Para Marcos Napolitano (2003, p. 168), esses conceitos substantivos estariam relacionados à história do tempo presente, perspectiva historiográfica valorizada no final do século XX para "fazer jus à voragem do tempo". Mesmo reconhecendo que a história não seja passível de neutralidade, e considerando que o professor não deva "submeter a análise do passado (ainda que recente) às paixões e opções políticas do presente" (Napolitano, 2003, p. 169), é comum percebermos a presença atuante da memória e de testemunhos pessoais, a exemplo da resposta apresentada pela estudante 11. O cuidado em relação a esse problema é o mesmo que se deve considerar para a seleção e uso de fontes associadas aos temas contemporâneos, a exemplo dos documentos audiovisual, sonoro e oral. Não obstante ao fascínio promovido, dependendo do uso, esses documentos podem reforçar alguns problemas na aprendizagem histórica, como o anacronismo, voluntarismo teórico e o descritivismo nominalista ${ }^{1}$ (Napolitano, 2003).

Finalmente, ao perscrutarmos a palavra "história" $(\mathrm{f}=18)$, encontramos uma variedade de assuntos levantados pelos/as participantes. Nem sempre são apontados de maneira direta, pois as respostas perpassam temporalidades e espaços diferentes:

Para mim, a Revolução Industrial e Revolução Francesa são duas das histórias que iniciou o nosso atual mundo. (estudante 144, gênero masculino, 16 anos, $1^{\circ}$ ano) Bom, eu não considero tão importante até porque são histórias antigas, e eu não tenho tanto interesse nessa matéria e não tenho tanto conhecimento, mas se for pra considerar, acho que os fatos mais marcantes, algo que agregou no agora. (estudante 147, gênero feminino, 15 anos, $1^{\circ}$ ano) 
Um assunto importante na história é quando é falado da vida antes de Cristo. (estudante 183, gênero masculino, 15 anos, $2^{\circ}$ ano)

As guerras, eu acho que foi o melhor momento da história. Porque um acontecimento em busca de igualdade. (estudante 20, gênero masculino, 13 anos, $9^{\circ}$ ano) Primeira Guerra Mundial e Segunda Guerra Mundial. Porque foi um dos momentos mais difícil da vida humana e os que foram mais marcantes da história. (estudante 221, gênero masculino, 16 anos, $3^{\circ}$ ano)

Considero mais importante o assunto do Descobrimento do Brasil, pois é o país onde eu vivo e eu acho que nós brasileiros devemos descobrir sobre onde vivemos! Saber as pessoas que passaram, que marcaram história, nossas origens, o que antigamente era feito no Brasil. (estudante 30, gênero feminino, 13 anos, $9^{\circ}$ ano)

Mais uma vez, podemos observar o interesse sobre assuntos que envolvem, principalmente, a história contemporânea. Por um lado, são levantados temas indefinidos, como fatos que agregam o agora ou a vida antes de Cristo. Por outro lado, observamos conceitos bastante específicos, a exemplo da Revolução Francesa, as Guerras Mundiais ou o descobrimento do Brasil - seria influência de uma abordagem da história integrada? De toda forma, essas ideias sugerem que a importância dos conceitos substantivos evocados reside na relação estabelecida com o tempo presente e com um ensino que valorize os direitos individuais e sociais, a exemplo da igualdade, liberdade religiosa e identidade étnica.

Não obstante as dificuldades epistemológicas implicadas na delimitação de marcos cronológicos para a história do tempo presente, podemos caracterizá-la como um período "durante o qual se produzem eventos que pressionam o historiador a revisar a significação que ele dá ao passado" (Hobsbawm, 1993, 1998 apud Delgado; Ferreira, 2013, p. 23). Portanto, ao se referir a um passado em processo de permanente atualização, o trabalho docente deve estar pautado na problematização de discursos que conduzam os estudantes à construção da crítica. Para isso, é necessário "lidar com a memória de uma maneira menos simplista do que o senso comum costuma apresentar" (Delgado; Ferreira, 2013, p. 31).

Embora não tenhamos analisado a prática docente, já que nosso objetivo foi tão somente perscrutar as concepções prévias dos estudantes acerca dos seus conhecimentos históricos, parece-nos que, nessa população, houve uma 
ênfase na perspectiva historiográfica que valoriza a história do tempo presente. Talvez isso tenha reforçado a presença de objetos ligados à história social, por meio da qual torna-se possível revelar condições de vida ou mesmo clamar por direitos e mobilizações sociais.

\section{HiSTÓRIA GERAL}

Neste momento, retomamos a CHD (Gráfico 1) relativa aos Assuntos Históricos para analisar a classe 2. A princípio, percebemos uma proximidade dessa categoria com o grupo descrito anteriormente, o que sugere a presença de ideias também relativas a uma história do tempo presente. Entretanto, ao considerar as expressões aqui reunidas, sobretudo as palavras "falar" ( $f=13)$ e "guerra" ( $\mathrm{f}=13$ ), cujo fascínio pela temática não podemos deixar de ressaltar, observamos uma série de conteúdos relacionados a uma história geral:

A história da América, porque fala como criaram as coisas de hoje em dia, saber um pouco do passado do meu país. (estudante 123 , gênero feminino, 13 anos, $8^{\circ}$ ano)

$\mathrm{O}$ assunto sobre Martinho Lutero, pois ele não tinha medo falar ou fazer o que era contra ou a favor da Igreja. (estudante 211, gênero feminino, 15 anos, $2^{\circ}$ ano) Feudalismo e Idade Média, porque é aonde nós falamos sobre hierarquia, o nobre, as posições de classes entre nobres, camponeses e os cleros. (estudante 108, gênero feminino, 12 anos, $7^{\circ}$ ano)

Eu gosto de falar sobre a corrupção onde eu e os meus colegas podemos conversar sobre os escândalos no nosso país. (estudante 172, gênero feminino, 15 anos, $2^{\circ}$ ano)

Segunda Guerra Mundial, porque fala sobre as economias do mundo e seus direitos. (estudante 235, gênero masculino, 17 anos, $3^{\circ}$ ano)

A Segunda Guerra Mundial porque pra nós poder analisar as crise que teve na guerra de 1929. (estudante 234, gênero feminino, 17 anos, $3^{\circ}$ ano)

Egito, Mesopotâmia, pois fala sobre os deuses dos povos, lendas, além de guerras e os fatos importantes para a sociedade do continente. (estudante 155, gênero masculino, 15 anos, $1^{\circ}$ ano)

As guerras, porque elas contam as besteiras que os líderes fizeram. (estudante 27, gênero e idade não identificados, $9^{\circ}$ ano) 
Apesar da semelhança com as narrativas agrupadas na classe 1, as ideias aqui elencadas parecem sugerir diferentes domínios, como a história da América e a história do Egito, ou mesmo dimensões específicas da história, como as dimensões econômica (Feudalismo), política (ações de líderes) e social (hierarquia social, corrupção). Conforme José d'Assunção Barros (2004), a divisão da história em "lotes" é uma construção humana, realizada no sentido de melhor compreender o mundo. Desse modo, o olhar dos/as estudantes acerca de assuntos considerados históricos também parece refletir algumas das perspectivas observadas na produção historiográfica escolar, responsáveis pela segmentação da história em distintos modos de ver, modos de fazer e de selecionar sujeitos e objetos históricos.

\section{HistóRIA DO BRASIL}

Diferentemente das categorias anteriores, os/as estudantes agrupados na classe 3 parecem ter plena certeza acerca da importância dos temas elencados. Aqui, as narrativas discorrem sobre o "Brasil", palavra cuja frequência ( $\mathrm{f}=19$ ) e poder de associação à classe $\left(\mathrm{x}^{2}=36,75\right)$ são as mais elevadas. Para isso, apropriam-se de alguns personagens e aspectos da história nacional para ressaltar a ideia de pertencimento ao país. É o que podemos observar a partir do uso do verbo "morar" ( $f=5)$ :

O assunto mais importante é do Brasil, porque é o país que eu moro. (estudante 105, gênero feminino, 12 anos, $7^{\circ}$ ano)

Pra mim é o descobrimento do Brasil porque foi um dos melhores assuntos de história pra mim e também é muito importante porque é sobre o país que eu moro. (estudante 122, gênero feminino, 12 anos, $8^{\circ}$ ano)

Em relação à história do Brasil, o tema mais lembrado foi o "descobrimento" ( $\mathrm{f}=11)$, cuja importância é associada à formação do país:

O descobrimento do Brasil porque mostra nossas origens. (estudante 195, gênero outros, 15 anos, $2^{\circ}$ ano)

Descobrimento do Brasil. Se não descobrisse o nosso país, nós não seríamos civilizados. (estudante 19, gênero masculino, 15 anos, $9^{\circ}$ ano) 
O descobrimento do Brasil porque conta como os portugueses chegaram ao Brasil e como foi para chegar até agora no século XXI. (estudante 192, gênero masculino, 15 anos, $2^{\circ}$ ano)

$\mathrm{O}$ descobrimento do Brasil porque se esse acontecimento não tivesse acontecido, os africanos não se juntariam os índios e talvez eu não tivesse nascido. (estudante 97, gênero feminino, 12 anos, $7^{\circ}$ ano)

Em estudo que buscou analisar os conhecimentos prévios de jovens estudantes acerca da história do Brasil, Regina Alegro (2008) também observou a predominância desse tema (descobrimento). Ao analisar a construção de diagramas produzidos pelos participantes, a pesquisadora conseguiu mapear os conceitos utilizados para atribuição de sentidos que expressavam a consciência histórica do grupo. Dessa forma, estabeleceu categorias descritivas que perpassaram a figura de Cabral, o encontro entre culturas e o processo de confronto e exploração do país.

De maneira semelhante, as narrativas aqui elencadas também evidenciam ideias em torno da chegada dos portugueses e destacam a presença de povos africanos e indígenas. Essas respostas parecem, contudo, valorizar a figura do homem branco europeu e o processo civilizatório a ele atribuído, além de ecoar uma antiga concepção de que a história do Brasil deveria ser escrita a partir de sua formação étnica - ideia surgida no Instituto Histórico e Geográfico Brasileiro (IHGB) e incorporada aos programas curriculares do Colégio Pedro II, no século XIX (Abud, 1997). Portanto, a concepção de história do Brasil aqui observada sugere a apreensão de uma historiografia escolar tradicional cujo "mito fundador", nas palavras de Cainelli e Barca (2018), seria a "chegada" (f $=4)$ de Cabral:

A chegada de Pedro Álvares Cabral no Brasil porque se ele não tivesse chegado aqui, os portugueses não estariam aqui e nada seria como hoje, as coisas evoluídas, e sem ele, nós não estaríamos aqui no Brasil. (estudante 114, gênero feminino, 13 anos, $8^{\circ}$ ano)

Ideias como essa poderiam revelar aspectos de um projeto republicano, desenvolvido sobretudo nas primeiras décadas do século XX, cujo objetivo era promover, no Ensino Primário, uma homogeneização da cultura escolar que atribuía ao passado uma visão única sobre a constituição da Nação, 
apropriando-se, quando preciso, dos conhecidos "heróis nacionais". Além disso, poderia refletir uma prática atrelada ao ensino secundário que atribuía ao Brasil uma origem europeia (Bittencourt, 2011b). De fato, esses elementos permeiam as concepções dos estudantes, mas é importante destacar a abordagem realizada sobre o segundo tema mais frequente nessas narrativas, a “escravidão" ( $f=7)$ :

A escravidão do negro porque foi daí que veio nós e o país de hoje. (estudante 34, gênero masculino, 14 anos, $9^{\circ}$ ano)

Para mim foi a escravidão africana porque gosto do assunto e queria saber melhor sobre eles. (estudante 126, gênero masculino, 13 anos, $8^{\circ}$ ano)

A libertação da escravidão no Brasil porque uma parte da minha família é negra e gosto de saber como eles se libertaram. (estudante 37, gênero masculino, 13 anos, $9^{\circ}$ ano)

Os sentidos atribuídos ao referido termo revelam não apenas um modo diferente de perceber a origem do Brasil - uma origem que não é iniciada diretamente na Europa - como também valorizam o pertencimento étnico dos participantes. Atrelada a esse tema, surge, ainda, a ideia de "liberdade" $(\mathrm{f}=4)$ :

Creio que é o que aconteceu com Tiradentes por ter sido morto para libertar pessoas. (estudante 02 , gênero feminino, idade não identificada, $9^{\circ}$ ano)

Da Princesa Isabel porque foi ela que libertou os escravos do Brasil. (estudante 04, gênero masculino, 14 anos, $9^{\circ}$ ano)

A independência do Brasil porque foi quando o Brasil se libertou e teve cada um a sua própria opinião. (estudante 29, gênero feminino, 13 anos, $9^{\circ}$ ano)

Mais uma vez, percebemos a valorização de temas (independência) e personagens (Tiradentes e princesa Isabel) que marcam uma historiografia escolar tradicional. Contudo, não podemos desconsiderar que tais elementos compõem uma "memória coletiva" que influenciou, possivelmente, a produção dessas "memórias individuais" (Halbwachs, 2006). A representatividade dessas ideias parece emergir quando os participantes são incitados a apontar o assunto histórico "mais importante", logo, a força da tradição escolar parece sobrepor qualquer forma relativizada de conhecimento. 


\section{CONSIDERAÇÕES FINAIS}

Ao escolherem assuntos considerados históricos, os/as participantes da pesquisa evidenciaram conhecimentos que, de maneira geral, poderiam ser associados a dois eixos: o da história geral e o da história do Brasil. Por um lado, destacou-se uma tendência historiográfica relacionada ao tempo presente, cuja ênfase recaiu sobre aspectos políticos e sociais; por outro, predominou uma percepção tradicional acerca da historiografia brasileira, por meio da qual se desenvolveu um olhar pautado no eurocentrismo e na evocação de heróis nacionais.

O primeiro movimento parece refletir o que ocorre na esfera da historiografia didática marcada por um modelo quadripartite de periodização. Nela, a ideia de tempo presente surge a partir de temas relacionados à história contemporânea, cujos conteúdos são tratados no último ano do Ensino Fundamental. É o que evidenciam as propostas curriculares brasileiras produzidas entre 2002 e 2012 (Freitas; Semeão; Oliveira, 2013). Nesses documentos, os marcos cronológicos do tempo presente oscilam entre o pós-guerra e a queda do muro de Berlim, além de mencionarem, implicitamente, o fim da ditadura militar, a globalização e o neoliberalismo como "formas de organização social, política e econômica representativas de um tempo diferenciado" (Freitas; Semeão; Oliveira, 2013, p. 9).

Apesar da imprecisão do conceito, conforme atestam os extensos debates em torno de sua terminologia, a ideia de "tempo presente" que prevalece nas propostas curriculares é aquela associada ao cotidiano ou à realidade do estudante, a um tempo "imediato" (Fico, 2016; Ferreira, 2000, 2002; Freitas; Semeão; Oliveira, 2013). As concepções analisadas neste artigo sugerem, portanto, uma aproximação com os "espaços de experiência" dos/as jovens, por meio dos quais se destaca um "passado" que ainda lhes "é contemporâneo" ou mesmo um "tempo" que lhes é "próprio" (Dosse, 2012; Rousso, 2009). Ao compreender a "noção evolutiva" que a "história do tempo presente" carrega, podemos ampliar a concepção de identidade elaborada pela historiografia didática e, com isso, buscar estratégias para suprir as carências de orientação no tempo sob uma perspectiva de alteridade em relação ao passado e suas possíveis relações de continuidade com o presente (Lagrou, 2007; Silva, 2017). 
Quanto às marcas da tradição evidenciadas nas narrativas dos/as participantes, podemos compreendê-las como um segundo movimento que reflete o peso da memória escolar. Embora a historiografia didática tenha sido beneficiada com renovações curriculares que buscaram promover um ensino mais significativo para a geração marcada pelo mundo tecnológico, o espaço destinado à história do Brasil permaneceu diminuto. Nem mesmo a tendência em associá-la a uma concepção de história integrada contribuiu com mudanças para uma explicação menos estrutural da história do Brasil. Isso resultou na apreensão de uma memória histórica nacional e patriótica conforme as concepções de ensino geradas no Brasil do século XIX (Cainelli; Barca, 2018).

Embora essa perspectiva acerca da história do Brasil possa revelar uma prática de ensino criticada e, mesmo, combatida, tanto por pesquisadores, quanto por professores do ensino Básico, é preciso considerar alguns elementos que nos ajudam a relativizar esses resultados: a categoria 3 é composta por apenas $27,75 \%$ das respostas consideradas na análise, e seus participantes são os mais jovens da pesquisa, com idades entre 12 e 13 anos (82,11\%), cursando o $7^{\circ}$ ou $8^{\circ}$ anos do Ensino Fundamental $(91,37 \%)$. Isso significa que os estudantes agrupados nessa categoria, possivelmente, ainda não conseguiram desenvolver uma visão global do passado, e suas concepções ainda estão relacionadas aos valores cultuados nos primeiros anos do processo de escolarização, tais como o culto aos símbolos patrióticos e as festas cívicas.

Entretanto, não podemos deixar de mencionar que, entre os estudantes mais velhos, cujo nível de escolaridade era maior, observamos o oposto, ou seja, a ênfase em temas contemporâneos. Nessa perspectiva, a história do Brasil não é mencionada diretamente, motivo pelo qual aventamos a possibilidade de uma prática de ensino que privilegiou uma história integrada "às avessas", isso porque, em vez de "integrar", em uma perspectiva sincrônica, a história nacional à história mundial, ocorre que as questões do país foram relegadas a um segundo plano. Conforme ressaltamos, nosso objetivo não foi entender as práticas de ensino, mas apenas as concepções dos jovens acerca dos conhecimentos históricos, competindo para isso tanto os saberes adquiridos em ambiente escolar, quanto os saberes da cultura histórica dos participantes. Ainda assim, é interessante perceber como esse aspecto tangenciou nosso estudo, sendo elucidado a partir de algumas falas dos/as participantes. 
Esperamos, por fim, que este trabalho possa suscitar o interesse de outros/ as pesquisadores/as acerca do conhecimento histórico de estudantes, das possibilidades de ensino em ambiente escolar, além dos desafios que a disciplina História lhes impõe. Acreditamos que, ao ouvir nossos jovens, seremos capazes de nos instrumentalizarmos para um melhor desenvolvimento de nossas atividades docentes.

\section{REFERENCIAS}

ABUD, Katia Maria. Currículos de História e políticas públicas: os programas de História do Brasil na escola secundária. In: BITTENCOURT, Circe (org.). O saber histórico na sala de aula. São Paulo: Contexto, 1997. (Repensando o ensino).

ABUD, Katia Maria. Narrativas, tempo e sujeitos históricos no ensino de história. Revista eletrônica Documento/Monumento, Cuiabá, v. 12, n. 1, p. 12-21, set. 2014. Disponível em: http://www.youblisher.com/p/1432360-Revista-Eletronica-Documento-Monumento. Acesso em: 19 maio 2015.

ALEGRO, Regina Célia. Conhecimento prévio e aprendizagem significativa de conceitos históricos no Ensino Médio. 2008. Tese (Doutorado em Educação) - Universidade Estadual Paulista "Júlio de Mesquita Filho" (Unesp). Marília, 2008.

BARROS, José d'Assunção. O campo da História: especialidades e abordagens. Petrópolis: Vozes, 2004.

BITTENCOURT, Circe Maria F. Abordagens históricas sobre a história escolar. Educação \& Realidade, Porto Alegre, v. 36, n. 1, p. 83-104, jan./abr. 2011 a. Disponível em: https://seer.ufrgs.br/educacaoerealidade/article/view/15136. Acesso em: 16 nov. 2015.

BITTENCOURT, Circe Maria F. Ensino de história: fundamentos e métodos. 4. ed. São Paulo: Cortez, 2011b.

BOGDAN, Robert C.; BIKLEN, Sari Knopp. Investigação qualitativa em educação: uma introdução à teoria e aos métodos. Porto: Porto Ed., 1994.

CAINELLI, Marlene; BARCA, Isabel. A aprendizagem da história a partir da construção de narrativas sobre o passado. Educação e Pesquisa, São Paulo, v. 44, 2018. Disponível em: http://www.scielo.br/pdf/ep/v44/1517-9702-ep-44-e164920.pdf. Acesso em: 26 nov. 2018.

CAMARGO, Brígido V.; JUSTO, Ana Maria. IRaMuTeQ: um software gratuito para análise de dados textuais. Temas em Psicologia, v. 1, n. 2, p. 513-518, 2013. Disponível em: http://pepsic.bvsalud.org/pdf/tp/v21n2/v21n2a16.pdf. Acesso em: 20 jul. 2016. 
DELGADO, Lucilia de Almeida N.; FERREIRA, Marieta de M. História do tempo presente e ensino de História. Revista História Hoje, São Paulo: Anpuh, v. 2, n. 4, p. 19-34, 2013. Disponível em: https://rhhj.anpuh.org/RHHJ/article/view/90. Acesso em: 8 nov. 2017.

DOSSE, François. História do tempo presente e historiografia. Tempo e Argumento, Florianópolis, v. 4, n. 1, p. 5-22, jan./jun. 2012. Disponível em: http://www.revistas. udesc.br/index.php/tempo/article/view/2175180304012012005/2014. Acesso em: 12 nov. 2018.

FERREIRA, Marieta de M. História do tempo presente: desafios. Cultura Vozes, Petrópolis, v. 94, n. 3, p. 111-124, maio/jun., 2000. Disponível em: http://bibliotecadigital.fgv.br/dspace/bitstream $/$ handle/10438/6842/517.pdf? sequence $=$ 1\&isAllowed=y. Acesso em: 8 nov. 2018.

FERREIRA, Marieta de M. História, tempo presente e história oral. Topoi, Rio de Janeiro, p. 314-332, dez. 2002. Disponível em: http://www.scielo.br/pdf/topoi/ v3n5/2237-101X-topoi-3-05-00314.pdf. Acesso em: 8 nov. 2018.

FICO, Carlos. História que temos vivido. In: MALERBA, Jurandir (org.). História e narrativa: a ciência e a arte da escrita histórica. Petrópolis: Vozes, 2016. p. 273-301.

FREITAS, Itamar; SEMEÃO, Jane; OLIVEIRA, Margarida. O contemporâneo e o tempo presente nos currículos escolares de História nos EUA e no Brasil (2002-2012). Cadernos do Tempo Presente, São Cristóvão, n. 11, 2013. Disponível em: https:// seer.ufs.br/index.php/tempo/article/view/2759. Acesso em: 25 maio 2013.

GERMINARI, Geyso D. Ideias de jovens do Ensino Médio sobre História: um estudo na perspectiva da Educação Histórica. Antíteses, v. 9, n. 18, p. 67-86, jul./dez. 2016. Disponível em: http://www.uel.br/revistas/uel/index.php/antiteses/article/ view/26537. Acesso em: 30 out. 2017.

GUIMARÃES, Selva. Revisitando a história da disciplina. In: GUIMARÃES, Selva. Didática e prática de ensino de história. 13. ed. revista e ampliada. Campinas: Papirus, 2012. p. 19-38.

HALBWACHS, Maurice. A memória coletiva. Tradução: Beatriz Sidou. São Paulo: Centauro, 2006.

HOBSBAWM, Eric J. Un historien et son temps présent. In: INSTITUT d'Histoire du Temps Présent. Ecrire l'histoire du temps présent. Paris: CNRS, 1993.

HOBSBAWM, Eric J. O presente como história. In: HOBSBAWM, Eric J. Sobre a História. São Paulo: Companhia das Letras, 1998. p. 243-255.

LAGROU, Pieter. Sobre a atualidade da história do tempo presente. In: PÔRTO, Gilson. História do tempo presente. Bauru: Edusc, 2007. p. 31-45. 
MORENO, Concha Fuentes. Concepciones de los alumnos sobre la Historia. Educar, Curitiba, p. 219-239, 2006. Número especial. Disponível em: https://revistas.ufpr. br/educar/article/viewFile/5539/4053. Acesso em: 26 nov. 2016.

NAPOLITANO, Marcos. Pensando a estranha história sem fim. In: KARNAL, Leandro (org.). História na sala de aula: conceitos, práticas e propostas. São Paulo: Contexto, 2003.

OLIVEIRA, Margarida Maria D. de. O direito ao passado (uma discussão necessária à formação do profissional de história). 2003. Tese (Doutorado em História) Universidade Federal de Pernambuco (UFPE). Recife, 2003.

PINA, Max Lanio M.; SILVA, Janaína B. As concepções de professores do Ensino Fundamental II sobre a Idade Média: uma análise sob a ótica da Educação Histórica. História \& Ensino, Londrina, v. 23, n. 2, p. 109-131, jul./dez. 2017. Disponível em: http://www.uel.br/revistas/uel/index.php/histensino/article/ view/29154/22904. Acesso em: 20 set. 2018.

RAMOS, Márcia Elisa T.; ALVES, Ronaldo C. Representações de História em jovens da Escola Básica e da Universidade: um estudo sobre pensamento histórico e identidade. Antíteses, v. 9, n. 18, p. 118-152, jul./dez. 2016. Disponível em: http://www. uel.br/revistas/uel/index.php/antiteses/article/view/27345. Acesso em: 30 out. 2017.

ROUSSO, Henry. Sobre a história do tempo presente: entrevista com o historiador Henry Rousso. Entrevistadores Silvia Maria Fávero Arend e Fábio Macedo. Tempo e Argumento, Florianópolis, v. 1, n. 1, p. 201-216, jan./jun. 2009. Disponível em: http://www.revistas.udesc.br/index.php/tempo/article/view/705. Acesso em: 13 nov. 2018.

SADDI, Rafael. O estado de suspensão na aprendizagem histórica: a força estética do conhecimento histórico na instauração de um momento sublime de consciência histórica. Revista História Hoje, v. 5, n. 9, p. 113-130, 2016. Disponível em: https:// rhhj.anpuh.org/RHHJ/article/view/247. Acesso em: 22 ago. 2018.

SÃO PAULO. Governo do Estado. Currículo do Estado de São Paulo: Ciências Humanas e suas tecnologias. São Paulo: Secretaria da Educação, 2012. Disponível em: http://www.educacao.sp.gov.br/a2sitebox/arquivos/documentos/236.pdf. Acesso em: 7 nov. 2015.

SCHMIDT, Maria Auxiliadora. História do ensino de história no Brasil: uma proposta de periodização. História da Educação, v. 16, n. 37, p. 92-117, maio/ago. 2012. Disponível em: https://seer.ufrgs.br/asphe/article/view/24245. Acesso em: 29 set. 2015.

SCHMIDT, Maria Auxiliadora. Perspectivas da consciência histórica e da aprendizagem em narrativas de jovens brasileiros. Tempos históricos, v. 12, p. 81-96, jan./jun. 2008. Disponível em: http://saber.unioeste.br/index.php/temposhistoricos/article/ viewFile/1945/1537. Acesso em: 15 out. 2016. 
SCHMIDT, Maria Auxiliadora; GARCIA, Tânia Maria F. B. A formação da consciência histórica de alunos e professores e o cotidiano em aulas de história. Cad. Cedes, Campinas, v. 25, n. 67, p. 297-308, set./dez. 2005. Disponível em: http://www.scielo.br/pdf/ccedes/v25n67/a03v2567.pdf. Acesso em: 15 out. 2016.

SILVA, Daniel P. O lugar do tempo presente na aula de história: limites e possibilidades. Tempo e Argumento, Florianópolis, v. 9, n. 20, p. 99-129, jan./abr. 2017. Disponível em: http://www.revistas.udesc.br/index.php/tempo/article/view/ 2175180309202017099. Acesso em: 19 nov. 2018.

STRAUSS, Anselm; CORBIN, Juliet. Pesquisa qualitativa: técnicas e procedimentos para o desenvolvimento de teoria fundamentada. 2. ed. Porto Alegre: Artmed, 2008.

\section{NOTA}

${ }^{1}$ Para Napolitano (2003, p. 179), esses problemas estão relacionados aos atos de: "cobrar dos agentes do passado valores que são contemporâneos nossos"; "aplicar teorias e sistemas ideológicos a priori para explicar o passado, desconsiderando processos sociais específicos e concretos"; "supervalorizar o anedótico e o factual".

Artigo recebido em 7 de julho de 2019. Aprovado em 11 de dezembro de 2019. 